\title{
APLICAÇÃO DA ENGENHARIA DE PRODUÇÃO NO DIAGNÓSTICO QUALITATIVO DAS AULAS REMOTAS DURANTE A PANDEMIA
}

\author{
https://dx.doi.org/10.48097/2674-8673.2022n6p03
}

João Carlos Nanes Lima Filho ${ }^{1}$

Lavínia Rayanne Severo da Silva ${ }^{2}$

\begin{abstract}
RESUMO
O ensino superior, assim como a educação no mundo, enfrentou um grande desafio no primeiro semestre do ano de 2020 em decorrência da pandemia de Covid-19 que modificou toda a estrutura da metodologia da educação presencial para uma modalidade remota de emergência. Durante este período algumas instituições de nível superior encararam o grande obstáculo da implementação dos meios digitais em suas aulas. Dentro desse contexto, após um ano nesse novo formato de modalidade de ensino, o presente artigo tem o intuito de trazer um breve diagnóstico e uma comparação sobre as dificuldades dos alunos nessas aulas.
\end{abstract}

Palavras-chave: Modalidades de Ensino. Pandemia. Qualidade. Aulas Remotas. Ensino Superior.

Data de submissão: $16 / 08 / 2021$

Data de aprovação: 22/09/2021

\begin{abstract}
Higher education, as well as education in the world, faced a major challenge in the first half of 2020 as a result of the Covid-19 pandemic that changed the entire structure of the classroom education methodology to a remote emergency mode. During this period, some higher education institutions faced the great obstacle of implementing digital media in their classes. Within this context, after a year in this new teaching modality format, this article aims to provide a brief diagnosis and a comparison of the students' difficulties in these classes.
\end{abstract}

Keywords: Teaching Modalities. Pandemic. Quality. Remote Lessons. University education.

\section{INTRODUÇÃO}

No primeiro semestre de 2020 o mundo deparou-se com a pandemia provocada pelo Coronavírus ou COVID-19. Os países e governos enfrentaram um desafio único com suas populações: o distanciamento social. Nesse contexto, as Instituições de Ensino Superior - IES

\footnotetext{
${ }^{1}$ Docente orientador do curso de Engenharia de Produção da Faculdade Metropolitana da Grande Recife. E-mail: joaonanes@metropolitana.edu.br

2 Discente do curso de Engenharia de Produção da Faculdade Metropolitana da Grande Recife.

E-mail: la.laraya@hotmail.com
} 
tiveram que suspender as atividades presenciais baseadas nos decretos dos governos estaduais e municipais, determinando a quarentena e sua reclusão em massa. Para que os estudantes não ficassem desassistidos durante o ano de 2020 as IES particulares e públicas recorreram ao modelo de ensino a distância $(\mathrm{EaD})$, na modalidade remota emergencial, de acordo com orientações estabelecidas pelo Ministério da Educação - MEC, constantes no decreto $343 / 2020$.

Este artigo passou por duas fases: a primeira ocorreu durante o mês de março a junho de 2020 quando foi elaborado o primeiro questionário no qual foram coletados dados sobre qual aplicativo de web conferência obteve maior adesão dos estudantes em participação e, no decorrer desse semestre, a instituição superior privada X passou pela transição dos aplicativos e plataformas de web conferência para a realização das aulas. Após um mês de testes semanais foi instituído pela IES X o aplicativo Google Meet como padrão para a aplicação da metodologia de ensino emergencial remoto.

A segunda fase do artigo formou-se a partir da coleta de dados por meio do aplicativo Survey Monkey com 50 alunos de uma instituição superior privada, localizada em Pernambuco, que fez a aplicação das suas aulas através da modalidade remota emergencial com embasamento jurídico na lei $n^{\circ}$ 14.040/2020 aos quais as IES obtêm um suporte para a realização das aulas até o final da pandemia e com o auxílio das Tecnologias Digitais da Informação e Comunicação - TDIC's, assistindo os alunos durante este período.

A pesquisa teve como objetivo fazer um comparativo sobre os impactos qualitativos e quantitativos com relação ao primeiro ano da pandemia nesta instituição de ensino superior e no semestre letivo do ano de 2021.1, obtendo, por meio de um questionário (que ficou aberto durante o período de abril de 2021 até o final do mês de maio do mesmo ano), uma avaliação da qualidade do ensino pela ótica dos alunos da IES. Esta avaliação foi usada como objeto de estudo, apresentando uma análise voltada para estabelecer indicadores de qualidade na nova metodologia de ensino superior que estava sendo aplicada durante a pandemia no estado de Pernambuco.

\section{ENSINO SUPERIOR BRASILEIRO}

$\mathrm{O}$ ensino superior no Brasil ocorreu tardiamente, iniciando-se durante o século XX em meados das décadas de 20 e 30 quando foram inseridas as primeiras instituições com cursos de graduação, mestrado e doutorado e depois de um período de tempo foram criadas as primeiras faculdades de ensino privado. 
Logo surgiu a Associação Brasileira de Mantenedoras de Ensino Superior - ABMES que teve início da década de 80 e foi criada com o intuito de representar nacionalmente a categoria e lutar por seus direitos que estão garantidos na Constituição Federal. (ECKEERT, CLARISSA; BENEDITO, CARLOS, 2002, p. 96).

\section{Ensino Presencial}

A modalidade de ensino presencial é a mais comum no território brasileiro em todos os níveis da educação, desde o fundamental ao superior. A mesma se caracteriza por ter um ambiente físico para a realização e aplicações das aulas, onde docentes e discentes se reúnem, utilizando-se de materiais físicos de apoio, sendo os conhecimentos efetivados por meio de trabalhos, avaliações e debates. (BATES, 2017).

\section{Ensino a Distância}

O Ensino a distância $(\mathrm{EaD})$ aplica-se ao aluno que está estudando sem estar presente fisicamente em uma sala de aula tradicional, cujo método proporciona maior flexibilidade de horário, economia, comodidade e inovação. Através da tecnologia é possível formar profissionais por todo o mundo, pois o estudante tem total independência de horários e organização dos seus assuntos, sendo as atividades gravadas e postadas antecipadamente nas suas respectivas plataformas. (MEC, 2007).

\section{Ensino Remoto}

A modalidade remota tem como característica principal o estudo com flexibilidade de local e com fácil acesso à plataforma, porém com um horário específico das aulas definido na matrícula do estudante. As mesmas acontecem online e em tempo real. Os professores, através de aparatos tecnológicos, exibem as suas aulas, aplicam as atividades, e os alunos apresentam as suas dúvidas que são respondidas simultaneamente. Esta modalidade conta com materiais atualizados e aulas dinâmicas, seguindo o cronograma instituído pela IES contratada pelo discente. (CARVALHO; CUNHA; QUIALA, 2020). 
Figura 1 - Diferenças entre as aulas de Educação a Distância (EaD) e Aulas Remotas

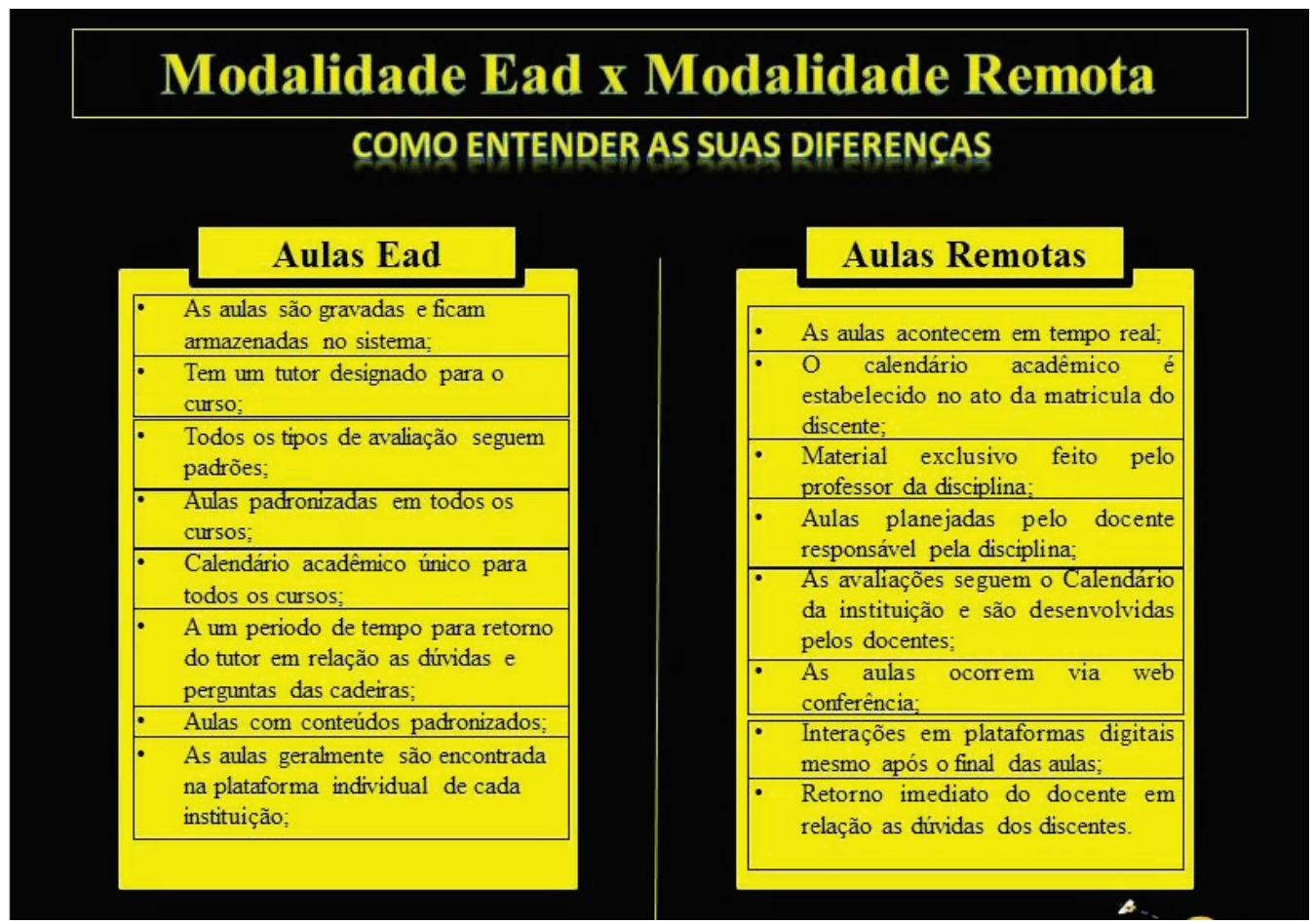

Fonte: Adaptado de Rededeensinojk, 2020.

No ano de 2020, durante o primeiro semestre, tornou-se necessário o isolamento social e o Ministério de Educação - MEC forneceu o apoio jurídico para dar continuidade a essas aulas com a portaria de $\mathrm{n}^{\mathrm{o}} 343$ do dia 17 de março de 2020 .

O MINISTRO DE ESTADO DA EDUCAÇÃO, no uso da atribuição que lhe confere o art. 87, parágrafo único, incisos I e II, da Constituição, e considerando o art. $9^{\circ}$, incisos II e VII, da Lei $\mathrm{n}^{\circ} 9.394$, de 20 de dezembro de 1996 , e o art. $2^{\circ}$ do Decreto $n^{\circ} 9.235$, de 15 de dezembro de 2017, resolve: Art. $1^{\circ}$ Autorizar, em caráter excepcional, a substituição das disciplinas presenciais, em andamento, por aulas que utilizem meios e tecnologias de informação e comunicação, nos limites estabelecidos pela legislação em vigor, por instituição de educação superior integrante do sistema federal de ensino, de que trata o art. $2^{\circ}$ do Decreto $\mathrm{n}^{\circ} 9.235$, de 15 de dezembro de 2017. $\S 1^{\circ} \mathrm{O}$ período de autorização de que trata o caput será de até trinta dias, prorrogáveis, a depender de orientação do Ministério da Saúde e dos órgãos de saúde estaduais, municipais e distrital. $\S 2^{\circ}$ Será de responsabilidade das instituições a definição das disciplinas que poderão ser substituídas, a disponibilização de ferramentas aos alunos que permitam o acompanhamento dos conteúdos ofertados bem como a realização de avaliações durante o período da autorização de que trata o caput. (ABMES, 2020).

Devido às medidas de prevenção ao contágio do Coronavírus a quarentena permaneceu ativa e as aulas presenciais seguiram suspensas. Com embasamento na lei 14.040/2020 e 
supervisão do Conselho Nacional de Educação - CNE, as IES receberam autorização para realização das aulas remotas até dezembro de 2021.

Faço saber que o Congresso Nacional decreta e eu sanciono a seguinte Lei: Art. $1^{\circ}$ Esta Lei estabelece normas educacionais a serem adotadas, em caráter excepcional, durante o estado de calamidade pública reconhecido pelo Decreto Legislativo $\mathrm{n}^{\circ} 6$, de 20 de março de 2020. Parágrafo único. O Conselho Nacional de Educação (CNE) editará diretrizes nacionais com vistas à implementação do disposto nesta Lei. Art. $3^{\circ}$ As instituições de educação superior ficam dispensadas, em caráter excepcional, da obrigatoriedade de observância do mínimo de dias de efetivo trabalho acadêmico, nos termos do caput e do $\S 3^{\circ}$ do art. 47 da Lei $\mathrm{n}^{\circ} 9.394$, de 20 de dezembro de 1996, para o ano letivo afetado pelo estado de calamidade pública referido no art. $1^{\circ}$ desta Lei, observadas as diretrizes nacionais editadas pelo $\mathrm{CNE}$ e as normas a serem editadas pelos respectivos sistemas de ensino, desde que: I seja mantida a carga horária prevista na grade curricular para cada curso; e II - não haja prejuízo aos conteúdos essenciais para o exercício da profissão. $\S 1^{\circ}$ Poderão ser desenvolvidas atividades pedagógicas não presenciais vinculadas aos conteúdos curriculares de cada curso, por meio do uso de tecnologias da informação e comunicação, para fins de integralização da respectiva carga horária exigida.

\section{Qualidade de Serviços}

A qualidade de serviços pode ser gerenciada com base nas dimensões em que se percebe confiabilidade, capacidade de prestar os serviços prometidos com confiança e exatidão, responsabilidade, disposição para auxiliar o cliente e oferecer uma prestabilidade, ou seja, superar qualquer expectativa de atendimento e prestação do que foi oferecido.

A qualidade tem um conceito subjetivo, pois se mantém diretamente ligada ao produto ou serviço oferecido ao cliente, por isso não se torna possível limitar a definição dessa palavra. Logo, ela transcende do fato de ser fabricado um bom produto ou executar um serviço padronizado e planejado. Durante a Primeira e a Segunda Guerra Mundial, em meados das décadas 1930 nos Estados Unidos, e 1940 no Japão, surgiram alguns métodos e aplicações reais da caracterização da qualidade. Alguns creem que a qualidade é a adequação ao uso, já outros trazem um conceito ocidental de que a qualidade se baseia em produtos e serviços que atendem ou excedem as expectativas do consumidor. Portanto, a qualidade não é só a realização de um serviço ou produção de um produto, mas também um estado de espírito para aqueles que vão consumi-los. (JURAN; NIORAKI KANO; 2015).

Durante os anos 1950 as empresas começaram a notar que a qualidade estava diretamente ligada à lucratividade, por isso elas iniciaram modelos de padronização para uma melhor conformidade dos produtos, adotando métodos de análise qualitativa no processo. "A gestão da qualidade total, como ficou conhecida essa nova filosofia gerencial, marcou o 
deslocamento da análise do produto ou serviço para a concepção de um sistema da qualidade". (CARVALHO; NASCIMENTO; MORAIS, 2010).

\section{Métodos de Análise e Solução de Problemas - MASP}

O Método de Análise e Solução de Problemas - MASP possui oito etapas: identificação do problema; observação; análise; plano de ação; ação; verificação; padronização e conclusão. Isso contribui para a identificação precisa da anomalia de qualquer processo, obtendo um feedback positivo, seja por uma ação corretiva ou minimizadora do problema. Esse sistema fornece um subsídio para a elaboração de análise e priorização dos problemas, situando a gestão e a equipe onde realmente se precisa de uma atenção mais aguçada no projeto, tendo uma melhoria contínua e padronizando os métodos.

Figura 2 - Método de Análise e Solução de Problemas e PDCA

\begin{tabular}{|c|c|c|c|}
\hline PDCA & FLUXOGRAMA & FASE DO MASP & OBJETIVO \\
\hline \multirow{4}{*}{$\mathbf{P}$} & & Identificação do problema & Definir o problema e verificar sua importância. \\
\hline & & Observação & Investigar as características do problema. \\
\hline & & Análise & Descobrir as causas fundamentais. \\
\hline & & Plano de Ação & Conceber um plano para as causas fundamentais. \\
\hline D & & Execução & Aplicar o plano para bloquear as causas. \\
\hline \multirow{2}{*}{ C } & & Verificação & Verificar se o bloqueio foi efetivo. \\
\hline & & \multicolumn{2}{|l|}{ Bloqueio foi efetivo? } \\
\hline \multirow{2}{*}{ A } & & Padronização & Prevenir contra o reaparecimento do problema. \\
\hline & & Conclusão & Recapitular o processo de solução de problemas para trabalhos futuros. \\
\hline
\end{tabular}

Fonte: Campos, 2009

A primeira fase consiste na identificação do problema, levando em consideração o histórico dessas complicações e a frequência em que elas ocorrem; o segundo momento, conhecido como observação, é a descoberta das características desses problemas através de uma coleta de dados e logo após é formado um cronograma de metas para investigar as suas causas. A terceira etapa, a análise, tem como objetivo principal determinar as causas fundamentais, sendo possível observar se o distúrbio no processo acontece nos mesmos horários ou dias, por exemplo, investigando quais são as peculiaridades do problema. $\mathrm{O}$ 
próximo passo traz um plano de ação com planejamento corretivo para a anomalia com uma ferramenta auxiliar da qualidade. Todo esse ciclo faz parte do plan do ciclo PDCA - P (Plan/Planejamento).

A $5^{\mathrm{a}}$ etapa do MASP é a ação, ou seja, o momento de executar as primeiras quatro fases do método de análise e solução de problemas, o que corresponde ao período D (Do/Execução). Por meio de uma nova verificação é confirmada a eficácia do planejamento e prática para correção dos problemas conhecido como C (Check/ Verificação), e por último a padronização do processo e a continuidade do ciclo PDCA A (Action/Ação), recapitulando a solução para os problemas futuros.

A Metodologia de Análise e Solução de Problemas (MASP) é uma forma estruturada de analisar e solucionar problemas da rotina diária das organizações, também conhecida como QC Story, oriunda do movimento da Qualidade Total no Japão. Trata-se de um desdobramento do método gerencial intitulado Ciclo PDCA - P (Plan/Planejamento), D (Do/Execução), C (Check/ Verificação) e A (Action/Ação), idealizado por Shewhart e divulgado por William Edwards Deming. Segundo Campos (2009), o PDCA permite criar, aprender, copiar e difundir conhecimentos, sendo o aprendizado a alma de sua utilização, transformando a organização numa escola, pois a busca por resultados melhores é paralela à busca do conhecimento. (Escola Nacional de Educação Pública - ENAP, 2015).

Figura 3 - Descrição do ciclo PDCA

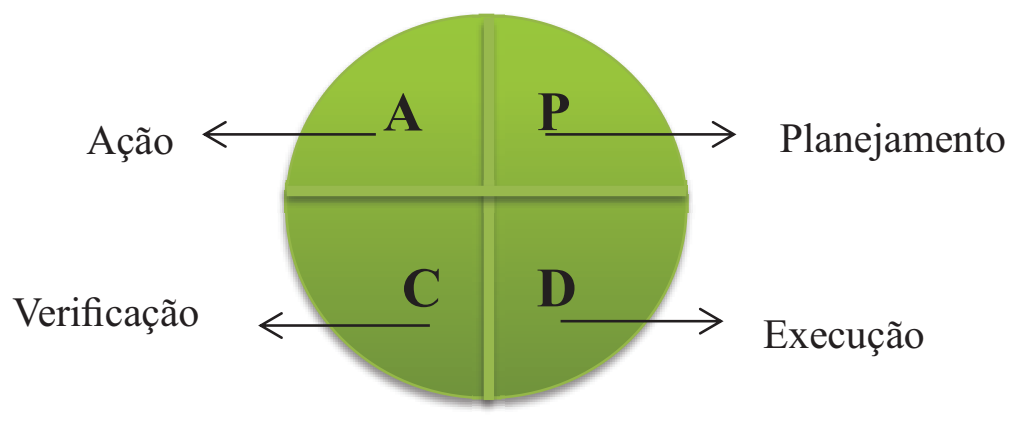

Fonte: Autoria própria

\section{Diagrama de Ishikawa}

O Diagrama de Ishikawa de causa e efeito ou escama de peixe, como é conhecido, foi criado na década de 60 por Karou Ishikawa. Essa ferramenta da qualidade proporciona uma avaliação por meio de gráficos das causas iniciais de um problema antes dele atingir uma proporção maior de efeitos negativos no processo. Esse método tem duas vertentes de solução: a identificação dos problemas, por meio de uma anomalia existente, e um 
levantamento sistemático, ou seja, é feito uma arrumação das causas para visualizar a melhor resolução no processo.

Figura 4 - Descrição do Diagrama de Ishikawa

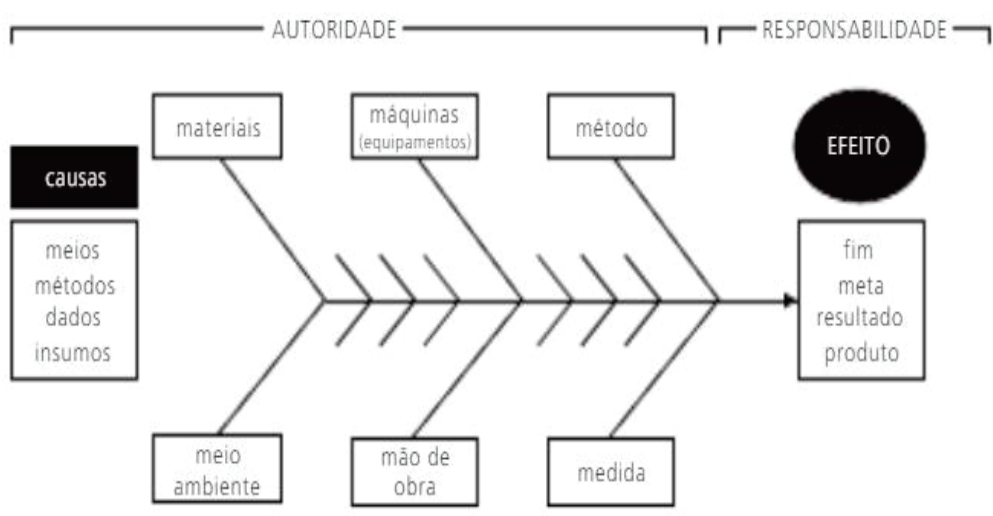

Fonte: Seleme \& Stadler, 2012.

\section{Brainstorming}

O Brainstorming ou "tempestade de ideias", como é conhecido, é um formato de geração de ideias em grupo com o intuito de estimular e incentivar a criar soluções. Com uma dinâmica de reuniões entre grupos, proporciona à empresa um conjunto de ideias inovadoras de forma criativa através do compartilhamento verbal durante os encontros, possibilitando debates e ajustes em todas as sugestões durante o processo. (TOMAZ et al., 2015).

\section{METODOLOGIA}

Este estudo se baseia em uma pesquisa realizada pelo aplicativo Survey Monkey com o objetivo de obter resultados qualitativos e quantitativos, fazendo, assim, um comparativo entre as coletas de dados do questionário que foi aplicado em março de 2020, o qual proporcionou a primeira análise do período de transição da metodologia do ensino presencial para o remoto emergencial. Em paralelo, o segundo questionário traz um comparativo de um ano após a implementação dessa modalidade de ensino acadêmico nas instituições superiores, explanando a perspectiva dos discentes na eficiência das aulas, cujo questionário foi aplicado em abril de 2021, com um tempo médio de resolução de cinco minutos.

Com as TDIC's - (Tecnologias Digitais de Informação e Comunicação) e o modelo da ferramenta MASP da área de qualidade foi feita a coleta dos dados para diagnosticar quais eram as principais dificuldades dos 50 alunos que se propuseram a responder as indagações, além da utilização do brainstorming (técnica para estimular a contribuição espontânea de 
ideias) para promover um comparativo de qualidade das aulas remotas no período de transição e no primeiro semestre de 2021.

Figura 5 - Descrição das quatro etapas trabalhadas no ciclo MASP através do fluxograma

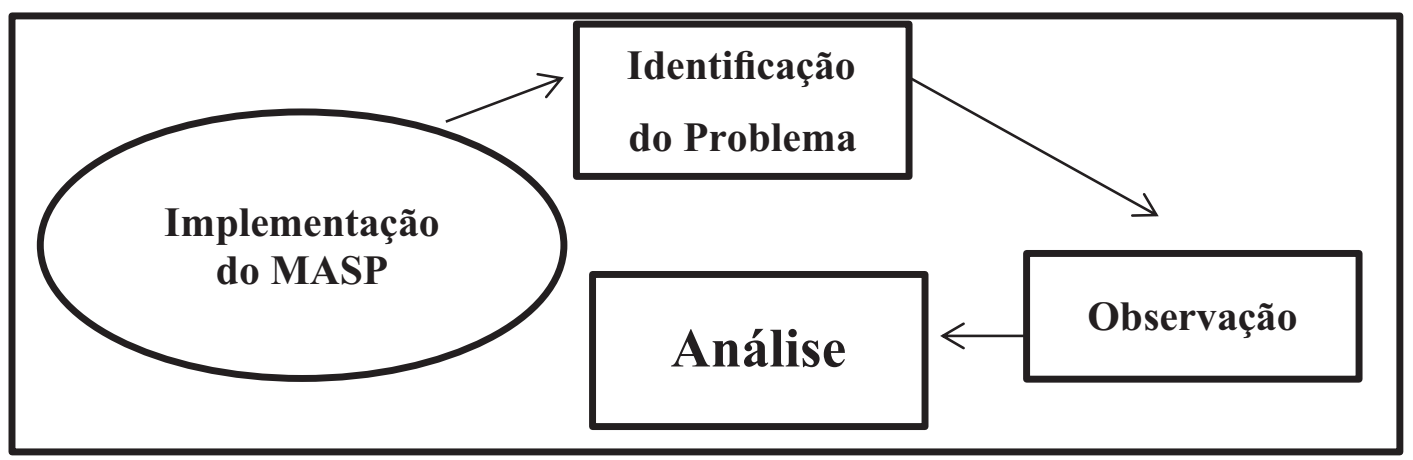

Fonte: Autoria própria

\section{Estudo de Caso}

A primeira etapa (figura 6) consistiu na coleta de respostas das questões: qual ponto de melhoria é crucial nas aulas EaD ou na modalidade remota? Qual a sua sugestão de aprimoramento? Houve uma boa adesão de retorno dos estudantes, sendo elaborado um brainstorming com as sugestões deles sobre as causas fundamentais das anomalias nas aulas remotas e $\mathrm{EaD}$, possibilitando a criação do diagrama de Ishikawa (Figura 7). Foi proposta a sistematização do problema e sua resolução através das suas respostas. Abaixo temos uma figura apresentando alguns pontos que foram abordados pelos estudantes.

Figura 6 - Feedback dos estudantes da IES

\begin{tabular}{|l|l|}
\hline \multicolumn{2}{|c|}{$\begin{array}{c}\text { QUAL PONTO DE MELHORIA É CRUCIAL NO PROCESSO DA MODALIDADE } \\
\text { EaD E MODALIDADE REMOTA? }\end{array}$} \\
\hline \multicolumn{2}{|c|}{ QUAL A SUA SUGESTÃO DE APRIMORAMENTO? } \\
\hline RESPOSTAS & DATAS \\
\hline Material de apoio. & $14 / 07 / 202018: 45 \mathrm{~h}$ \\
\hline Aplicativos mais viáveis, que não travem tanto. & $09 / 02 / 202014: 28 \mathrm{~h}$ \\
\hline Padronização. & $01 / 07 / 2020 \quad 00: 13 \mathrm{~h}$ \\
\hline $\begin{array}{l}\text { A realização dos cálculos em um quadro } \\
\text { durante as aulas. }\end{array}$ & $13 / 07 / 2020 \quad 20: 19 \mathrm{~h}$ \\
\hline $\begin{array}{l}\text { A flexibilidade dos docentes em alguns pontos } \\
\text { durante as aulas. Em questão do sistema um } \\
\text { padrão único de plataforma. }\end{array}$ & $13 / 07 / 202018: 25 \mathrm{~h}$ \\
\hline A atualização das aulas gravadas no portal. & $14 / 07 / 202018: 13 \mathrm{~h}$ \\
\hline A falta de organização das informações. & $14 / 07 / 202018: 10 \mathrm{~h}$ \\
\hline
\end{tabular}

Fonte: Autoria própria 
De acordo com os dados coletados foi produzido o diagrama de Ishikawa ou gráfico de causa e efeito (Figura 7), descrevendo as principais causas das dificuldades dos discentes durante a aplicação das aulas remotas emergenciais. O questionário obteve a participação efetiva de alunos dos cursos de Engenharia de Produção (46\%), Direito (34\%), Pedagogia $(12 \%)$ e Logística $(8 \%)$.

Figura 7 - Diagrama de Ishikawa identificando as principais causas de anomalias

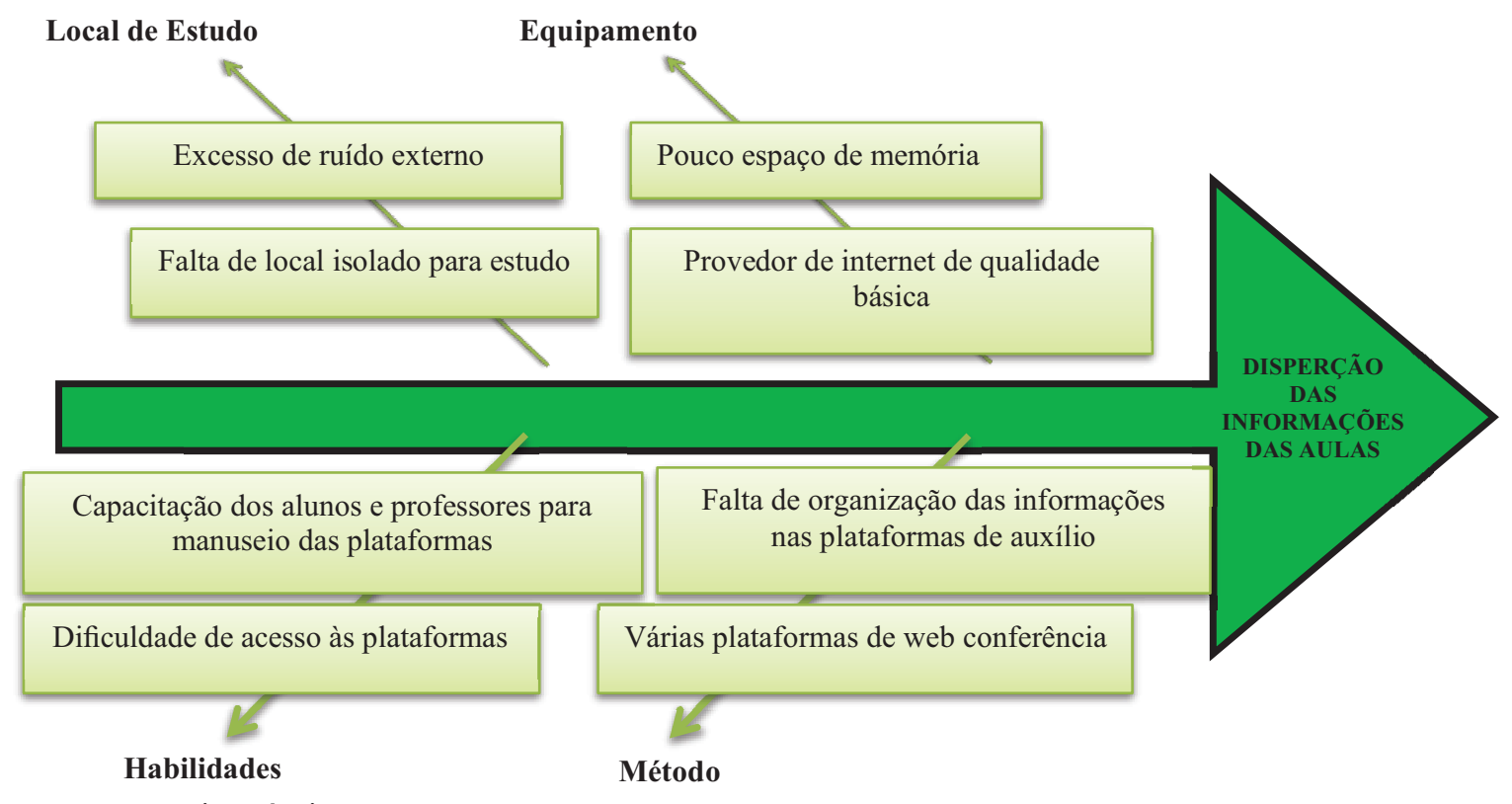

Fonte: autoria própria

Acima, o gráfico de Ishikawa descreve as principais causas que corroboram para a dispersão da informação: capacitação dos docentes e discentes para o manuseio da plataforma de web conferência no período de transição; a falta de organização das informações na plataforma oficial da instituição; o excesso de ruído no local de estudo, causando interrupções; a variedade de aplicativos para assistir as aulas remotas, provocando transtorno de acesso nos momentos de aula, tendo como uma consequência atrasos e perda de assuntos das respectivas matérias. A habilidade de manuseio com os equipamentos de acesso utilizados obteve respostas das aptidões dos estudantes da IES como básica (12,73\%), média (61,82\%) e avançada $(25,45 \%)$.

Após o diagrama de Ishikawa foram criados grupos no aplicativo de troca de mensagem WhatsApp para estabelecer um local específico para a publicação de informações referentes a cada disciplina (Figura 8) e de fácil acesso por parte do estudante, possibilitando o maior engajamento dos alunos durante as aulas e, consequentemente, melhorando o desenvolvimento deles no manuseio das plataformas como Google Meet e Classroom. 
O Grupo no WhatsApp continha as seguintes informações: link do drive onde é armazenado o material de apoio, segregado por disciplina; as gravações das aulas nas plataformas de web conferência; o endereço por link do grupo com o intuito de obter maior engajamento dos discentes; o ID da turma criada pelo professor no aplicativo Classroom; a senha de ingresso para o aluno acompanhar as atividades pendentes e enviá-las no prazo estipulado pelo professor; e por fim o link da aula no aplicativo de web conferência (Figura $8)$.

Figura 8 - Grupo criado com as instruções necessárias para a participação dos discentes nas aulas

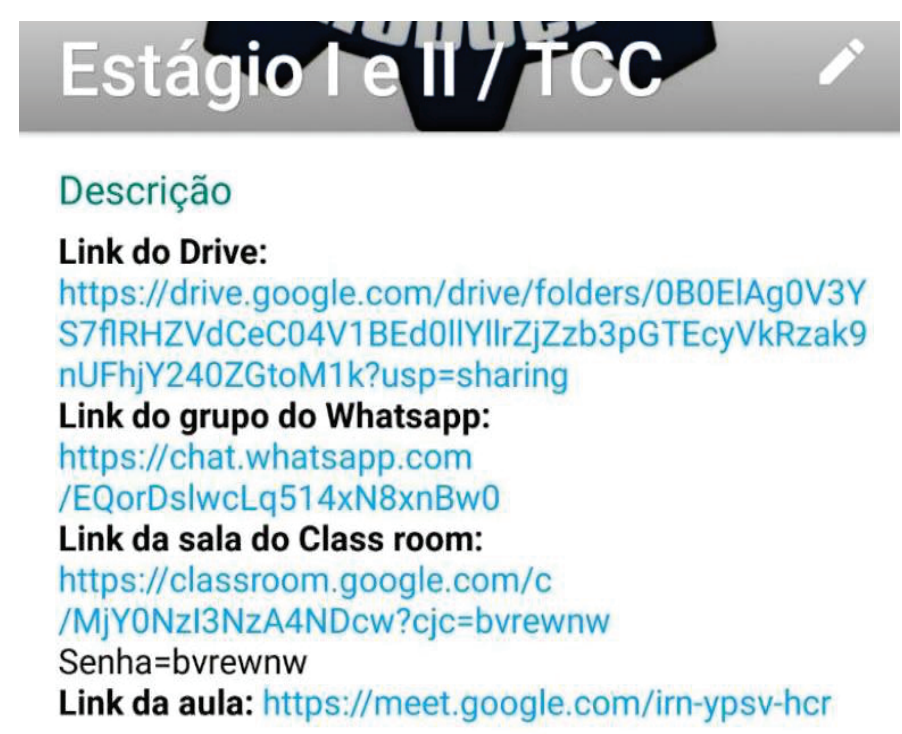

Fonte: Whatsapp, 2021

A plataforma de web conferência que mais obteve aceitabilidade pelos discentes nas duas pesquisas foi o Google Meet devido à facilidade e praticidade de acesso (Figura 9). O mesmo permite ao docente marcar reuniões com seus alunos em formato de agenda e proporciona a explanação do material expositivo (apresentações em slides) com mais facilidade. A figura 09 faz uma comparação com a figura 10 em relação à popularidade dos aplicativos de web conferência que foram testados durante o período de transição das aulas presenciais para a modalidade remota emergencial. 
Figura 9 - Gráfico das plataformas utilizadas para aplicação das aulas remotas em 2020.1 Qual a plataforma que você utiliza para estudar na modalidade remota?

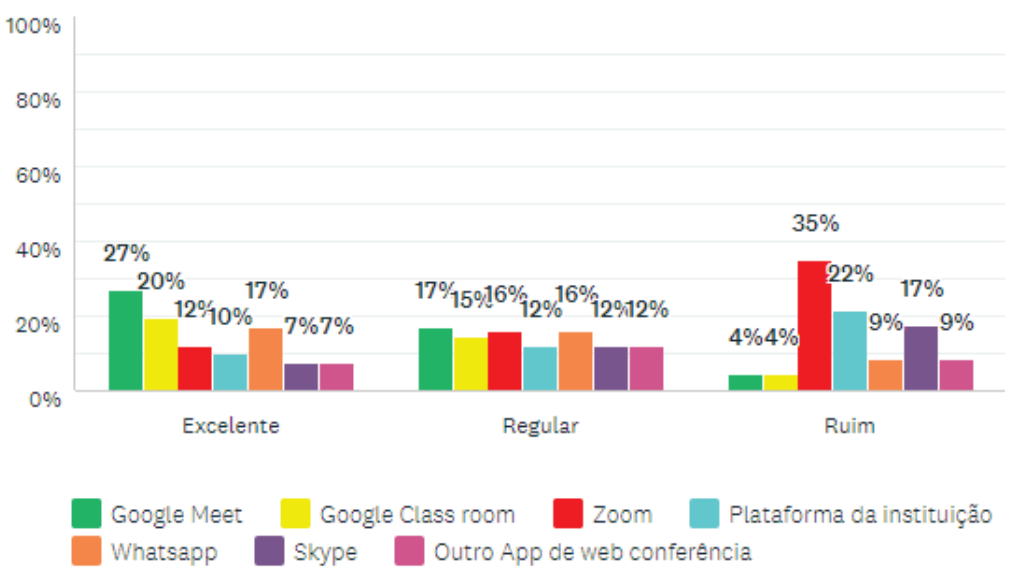

Fonte: Survey Monkey, 2020

De acordo com o feedback apresentado (figura 11) na segunda pesquisa nota-se que depois da transferência de uma modalidade para outra, dentro de um semestre, os discentes identificaram que o aplicativo que mais atendia as suas necessidades de praticidade no acesso à plataforma, agendamento e gravações das aulas era o aplicativo Google Meet. O primeiro gráfico refere-se ao período de implementação e transição das plataformas de web conferência na instituição.

Figura 10 - Gráfico da porcentagem das plataformas utilizadas para aplicação das aulas remotas em 2021.1

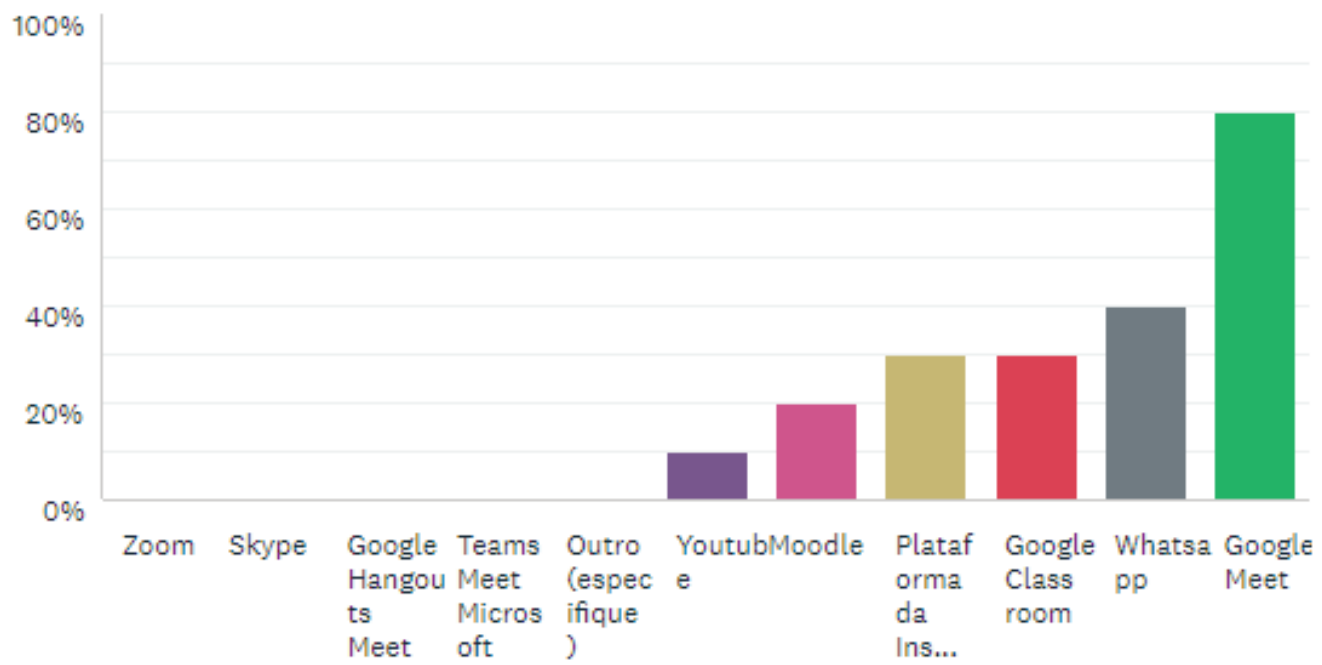

Fonte: Survey Monkey, 2020. 
Com as plataformas Zoom e Google Classroom ocorreram as primeiras tentativas para a realização das aulas remotas, porém, de acordo com um grupo de $20 \%$ dos estudantes, não foi aprovada a qualidade do aplicativo Zoom. Logo em seguida a instituição colocou em teste o aplicativo Google Meet e obteve uma resposta positiva por parte dos alunos, tornando o modelo de web conferência para a apresentação das aulas.

Figura 11 - Gráfico das duas plataformas online que os discentes mais se adaptaram no semestre de 2021.1

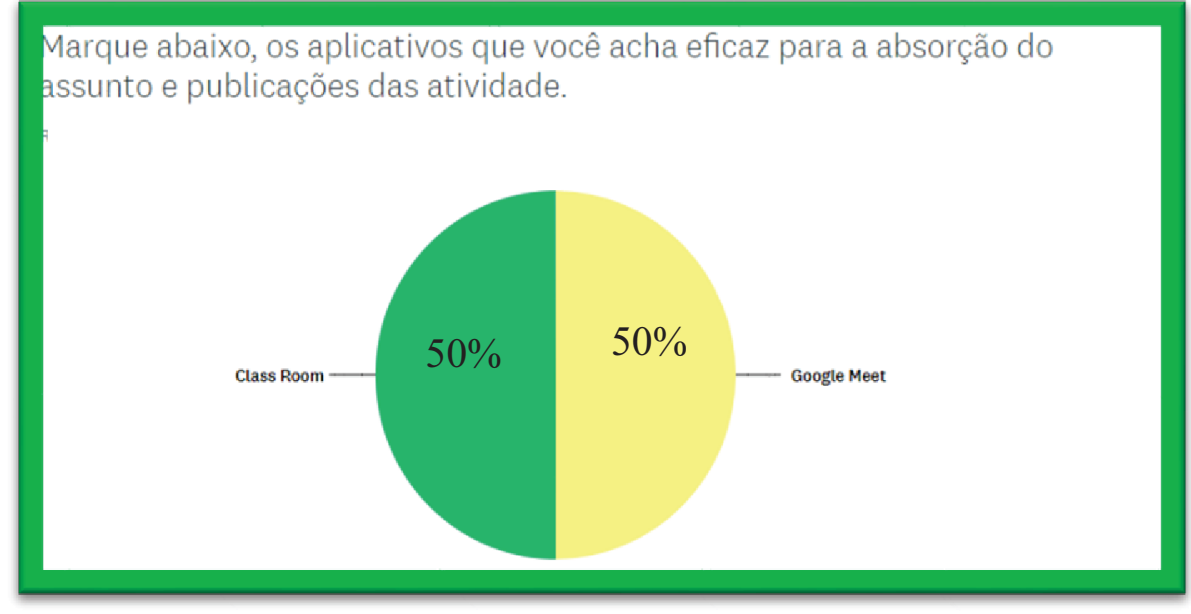

Fonte:_Survey Monkey, 2021

Foi aplicada a última fase da pesquisa, que corresponde à terceira etapa do método PDCA (a verificação), com aplicação de grupos em aplicativos de troca de mensagens, fixação do mural de informações para o acompanhamento e maior engajamento dos alunos durante as aulas, e padronização da plataforma de web conferência. É notório, de acordo com a pesquisa, que a IES possui um índice de melhoria nas aulas remotas devido a identificação dessas anomalias no processo e um feedback dos discentes em relação à qualidade das aprendizagens aplicadas durante o primeiro semestre de 2021. (Figura 12).

O Gráfico abaix o mostra que uma porcentagem de $60 \%$ dos alunos se adaptaram bem e $40 \%$ ainda estavam se adequando ao novo método de ensino EaD remoto. 
Figura 12 - Gráfico sobre a adaptação à modalidade de ensino remoto e EaD que os discentes mais se adequaram no semestre de 2021.1

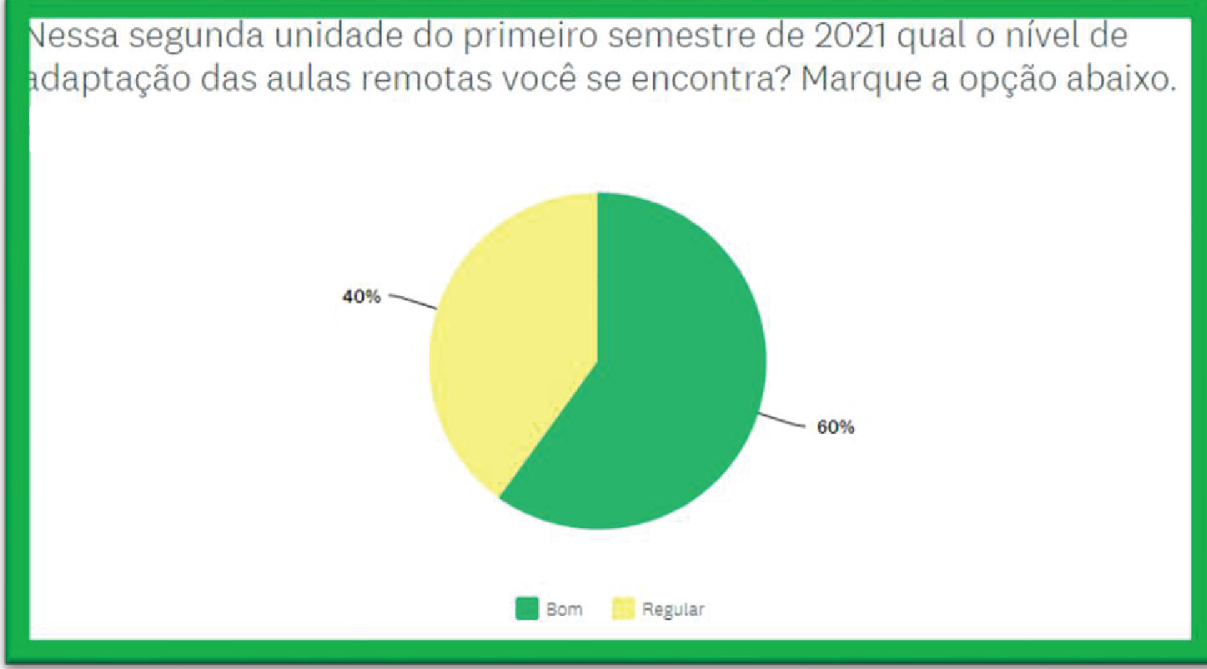

Fonte: Survey Monkey, 2021

\section{CONSIDERAÇÕES FINAIS}

Devido às circunstâncias da pandemia não foi possível uma participação mais ampla na pesquisa com todas as turmas da instituição, porém com bases nos dados apresentados durante o artigo, concluiu-se uma análise qualitativa e quantitativa sobre os níveis de adaptação do ensino presencial para a transição das metodologias remotas e $\mathrm{EaD}$, observando que mais alunos estão engajados de forma participativa e efetiva nas aulas, o que possibilitou respostas mais diretas de acordo a realidade nas salas virtuais dos discentes de ensino de nível superior.

\section{REFERÊNCIAS}

ABED. Ensino a distância e cursos online: conheça as modalidades. Disponível em: http://abed.org.br/blog/modalidades-ead-cursos-online/. Acesso: 5 Jul. 2020.

ABMES. Aulas remotas ou EaD? Disponível em: https://abmes.org.br/noticias/detalhe/3705/aulas-remotas-ou-ead-. Acesso: 12 Jun. 2020.

ARIOLI, E. E. Análise e Solução de Problemas - O Método da Qualidade Total com Dinâmica de Grupo. Rio de Janeiro: Qualitymark, 1998.

CAMPOS, Vicente Falconi. TQC: Gerenciamento da Rotina do Trabalho do Dia a Dia. Rio de Janeiro: 1994.

CARPINETE, L. C. R. Gestão da Qualidade: Conceitos e Técnicas. São Paulo: Atlas S. A, 2010. 
ECKEERT, Clarissa; BENEDITO, Carlos. Ensino Superior no Brasil: uma visão abrangente. p. 96-100, Brasília, 2002.

LAS CASAS, A. L. Qualidade total em serviços. 6. ed. São Paulo: Atlas, 2008.

SELEME, Robson; STADLER, Humberto. Controle da Qualidade: As Ferramentas Essenciais. Curitiba: XIBPEX, 2012.

TOMAZ, Gustavo; TEZA, Pierry; APARECIDA, Gertrudes; SOUZA, João; Métodos, Técnicas e Ferramentas para Inovação: Brainstorming no Contexto da Inovação. 2015. 